\title{
Formulation design, optimization \& in vitro evaluation of novel orodissolving tablets of efavirenz for hiv infections
}

\author{
T. Ayyappan ${ }^{1}$, C. Poojitha ${ }^{1 *}$ and T. Vetrichelvan \\ ${ }^{I}$ Department of Pharm cs, Adhiparasakthi college of Pharmacy, Melmaruvathur-603 319.
}

\begin{abstract}
In the present work, orodissolving tablets of Efavirenz were prepared by direct compression method with a view to enhance patient compliance. A 23 full factorial design was applied to investigate the combined effect of three formulation variables. Amount of crospovidone, croscarmellose sodium and sodium starch glycolate were used as superdisintegrant material along with direct compressible mannitol to enhance mouth feel. The prepared batches of tablets were evaluated for hardness, friability, weight variation, disintegration time, wetting time, drug content and in-vitro dissolution studies. Based on wetting time, disintegration time, the formulation containing crospovidone $(5 \% \mathrm{w} / \mathrm{v})$, carscarmellose sodium $(5 \% \mathrm{w} / \mathrm{v})$ and sodium starch glycolate $(8 \% \mathrm{w} / \mathrm{v})$ was found to be promising and tested for in-vitro drug release pattern (in $0.1 \mathrm{~N} \mathrm{HCl}$ ), short term stability and drug- superdisintegrants interaction. Surface response plots are presented to graphically represent the effect of independent variables (conc. of superdisintegrants) on the in-vitro dissolution time. The validity of the generated mathematical model was tested by preparing extra-design check point formulation. The formulation showed nearly faster drug release compared to the conventional commercial tablet formulation. Stability studies on the optimized formulation indicated that there was no significant change found in physical appearance, hardness, disintegration time, drug content and in-vitro drug release.
\end{abstract}

Keywords: $2^{3}$ full factorial design; Crospovidone; Croscarmellose sodium and sodium starch glycolate; Efavirenz; Orodissolving tablets

\section{Introduction}

A fast dissolving tablet system can be defined as a dosage form for oral administration, which when placed in mouth, rapidly dispersed or dissolved and can be swallowed in form of liquid. The major problem faced by many patients with conventional tablets dosage form is difficulty in swallowing. This problem is more apparent when drinking is not easily available to the patient taking medicine. Hence, patients may not comply with prescription, which results in high incidence of in effective therapy. Recently fast dissolving formulation is popular as Novel Drug Delivery Systems because they are easy to administer and lead to better patient compliance. Pediatric and geriatric patient have difficulty in swallowing the conventional dosage forms. These dosage forms dissolve or disintegrate in the oral cavity within a minute without water or chewing. For these formulations, the small volume of saliva is usually sufficient to result in tablet disintegration in the oral cavity. The medication can then be absorbed partially or entirely into the systemic circulation through blood vessels in the sublingual mucosa, or it can be swallowed as a solution to be absorbed from the gastrointestinal tract. Bioavailability of the drug from this delivery system is significantly greater than conventional tablets.
Efavirenz is a synthetic purine derivative used as an HIV-1 specific, non nucleoside reverse transcriptase inhibitor (NNRTI). It is an antiretroviral agent indicated for the treatment of human immune deficiency virus type-1 (HIV-1) infection which is not soluble in water and lower absorption in gastric fluid .In order to improve the solubility and oral absorption of the drug in gastric fluid enhancing its dissolution orodissolving tablet (ODT) formulation by direct compression method is designed and evaluated in this study.

\section{Materials \& methods}

Efavirenz was gift sample from Hetero drugs Ltd, Hyderabad, crospovidone (cp), croscarmellose sodium (ccs) and sodium starch glycolate(ssg) were gift samples from Tristar Pharmaceuticals, puducherry, directly compressible Mannitol, Aerosil, magnesium stearate, Aspartame, flavor(pine apple), microcrystalline cellulose pH102 from Loba Chemicals, Mumbai. All other materials used were of analytical reagent grade.

\footnotetext{
*Corresponding author: E-mail: poojareddy.ch@gmail.com
} 
Preparation of efavirenz orodissolving tablets

Orodissolving tablets of Efavirenz were prepared by direct compression method. According to the formula shown in Table I, all the ingredients with drug except magnesium stearate were taken in the mortar. The powder blend was then mixed well by using mortar and pestle for 15 to 30 minutes and then each mixture was passed through $\# 80$ sieves. Finally magnesium stearate was added as a
Cadmach tablet compression machine to produce flat faced tablets weighing $400 \mathrm{mg}$ each with the diameter of $8 \mathrm{~mm}$.

\section{Flow properties of blend}

The flow properties of blend (before compression) were characterized in terms of angle of repose, Carr index \& Hausner ratio (Table II). For determination of angle of repose $(\theta)$, the blend were poured through the walls of a

\section{Table I. Factorial design formulations of odt of efavirenz}

\begin{tabular}{lccccccccc}
\hline \multirow{2}{*}{$\begin{array}{l}\text { Ingredients } \\
\text { (mg/tablet) }\end{array}$} & \multicolumn{1}{c}{ Formulation Code } \\
\cline { 2 - 9 } & F1 & F2 & F3 & F4 & F5 & F6 & F7 & F8 & F9 \\
\hline Efavirenz & 200 & 200 & 200 & 200 & 200 & 200 & 200 & 200 & 200 \\
Crospovidone & 1 & 2.5 & 1 & 2.5 & 1 & 2.5 & 1 & 2.5 & 1.75 \\
Croscarmellose sodium & 1 & 1 & 4 & 4 & 1 & 1 & 4 & 4 & 2.5 \\
Sodium Starch Glycolate & 0.5 & 0.5 & 0.5 & 0.5 & 2.5 & 2.5 & 2.5 & 2.5 & 1.5 \\
Mannitol & 5 & 5 & 5 & 5 & 5 & 5 & 5 & 5 & 5 \\
Aerosil & 0.5 & 0.5 & 0.5 & 0.5 & 0.5 & 0.5 & 0.5 & 0.5 & 0.5 \\
Magnesium stearate & 0.25 & 0.25 & 0.25 & 0.25 & 0.25 & 0.25 & 0.25 & 0.25 & 0.25 \\
Aspartame & 2.5 & 2.5 & 2.5 & 2.5 & 2.5 & 2.5 & 2.5 & 2.5 & 2.5 \\
Flavour & 1 & 1 & 1 & 1 & 1 & 1 & 1 & 1 & 1 \\
Microcrystalline cellulose & 188.25 & 186.75 & 185.25 & 183.25 & 186.25 & 184.75 & 183.25 & 181.75 & 185 \\
Total & 400.00 & 400.00 & 400.00 & 400.00 & 400.00 & 400.00 & 400.00 & 400.00 & 400.00 \\
\hline
\end{tabular}

lubricant and mixed thoroughly; microcrystalline cellulose was used as diluents and also acts as a disintegrant. The resultant mixture was compressed using 16 stations funnel, which was fixed at a position such that its lower tip was at a height of exactly $2.0 \mathrm{~cm}$ above hard surface. The blends were poured till the time when upper tip of the pile

Table II. Evaluation of micromeritic properties of powder blend

\begin{tabular}{cccccc}
\hline $\begin{array}{c}\text { Formulation } \\
\text { Code }\end{array}$ & $\begin{array}{c}\text { Angle of } \\
\operatorname{Repose}\left({ }^{\circ}\right) \pm \mathrm{SD}\end{array}$ & $\begin{array}{c}\text { LBD }(\mathrm{gm} / \mathrm{ml}) \\
\pm \mathrm{SD}\end{array}$ & $\begin{array}{c}\mathrm{TBD}(\mathrm{gm} / \mathrm{ml}) \\
\pm \mathrm{SD}\end{array}$ & $\begin{array}{c}\text { Carr's Index }(\%) \\
\pm \text { SD }\end{array}$ & $\begin{array}{c}\text { Hausner's Ratio } \\
\pm \text { SD }\end{array}$ \\
\hline F1 & $21.10 \pm 0.762$ & $0.61 \pm 0.005$ & $0.71 \pm 0.002$ & $12.41 \pm 0.004$ & $1.15 \pm 0.015$ \\
F2 & $20.66 \pm 0.762$ & $0.59 \pm 0.005$ & $0.72 \pm 0.003$ & $12.66 \pm 0.045$ & $1.15 \pm 0.011$ \\
F3 & $20.76 \pm 0.467$ & $0.62 \pm 0.005$ & $0.71 \pm 0.006$ & $12.41 \pm 0.002$ & $1.15 \pm 0.010$ \\
F4 & $23.07 \pm 0.098$ & $0.62 \pm 0.005$ & $0.71 \pm 0.020$ & $13.88 \pm 0.002$ & $1.17 \pm 0.010$ \\
F5 & $21.38 \pm 0.710$ & $0.63 \pm 0.000$ & $0.72 \pm 0.040$ & $12.65 \pm 0.003$ & $1.16 \pm 0.000$ \\
F6 & $20.81 \pm 0.884$ & $0.64 \pm 0.005$ & $0.74 \pm 0.003$ & $12.38 \pm 0.005$ & $1.14 \pm 0.050$ \\
F7 & $20.35 \pm 0.282$ & $0.62 \pm 0.000$ & $0.73 \pm 0.006$ & $12.61 \pm 0.060$ & $1.15 \pm 0.010$ \\
F8 & $20.75 \pm 0.616$ & $0.62 \pm 0.005$ & $0.70 \pm 0.004$ & $14.14 \pm 0.013$ & $1.15 \pm 0.011$ \\
F9 & $21.06 \pm 0.652$ & $0.62 \pm 0.005$ & $0.73 \pm 0.005$ & $12.88 \pm 0.011$ & $1.15 \pm 0.010$ \\
\hline
\end{tabular}


surface touched the lower tip of the funnel. The $\tan ^{-1}$ of the (height of the pile/radius of its base) gave the angle of repose. Blends were poured gently through a glass funnel into a graduated cylinder cut exactly to $10 \mathrm{ml}$ mark. Excess blend was removed using a spatula and the weight of the cylinder with pellets required for filling the cylinder volume was calculated. The cylinder was then tapped from a height of $2.0 \mathrm{~cm}$ until the time when there was no more decrease in the volume. Bulk density (BD) and tapped density (TBD) were calculated. Hausner ratio (HR) and Carr's index were calculated according to the two equations given below:

$\mathrm{HR}=\mathrm{TBD} / \mathrm{BD}$

Carr's Compressibility Index $(\%)=[($ TBD-LBD $) / T B D]$ x100

\section{Evaluation of orodissolving tablets of efavirenz}

All the tablets were evaluated for different parameters such as thickness, diameter, weight variation, hardness, friability, drug content, disintegration time, wetting time, and in vitro dissolution study (Table III).

\section{Thickness \& diameter}

Ten tablets from each formulation were selected randomly and their thickness and diameter was measured with a screw gauge.

Table III. Evaluation of factorial design orodissolving tablet formulations

\begin{tabular}{|c|c|c|c|c|c|c|c|c|c|}
\hline \multirow{2}{*}{ Parameters } & \multicolumn{9}{|c|}{ Formulation Code } \\
\hline & $\mathrm{F} 1$ & F2 & F3 & F4 & F5 & F6 & F7 & F8 & F9 \\
\hline Thickness (mm) & $4.44 \pm$ & $4.45 \pm$ & $4.49 \pm$ & $4.48 \pm$ & $4.48 \pm$ & $4.47 \pm$ & $4.45 \pm$ & $4.44 \pm$ & $4.44 \pm$ \\
\hline$\pm \mathrm{SD}$ & 0.01 & 0.02 & 0.07 & 0.01 & 0.05 & 0.09 & 0.11 & 0.08 & 0.11 \\
\hline Weight Variation (\%) & $2.37 \pm$ & $2.26 \pm$ & $2.22 \pm$ & $2.38 \pm$ & $2.01 \pm$ & $2.32 \pm$ & $2.07 \pm$ & $2.12 \pm$ & $2.13 \pm$ \\
\hline$\pm \mathrm{SD}$ & 1.33 & 1.29 & 1.40 & 1.02 & 1.43 & 1.20 & 1.03 & 1.06 & 1.02 \\
\hline Hardness $\left(\mathrm{kg} / \mathrm{cm}^{2}\right.$ & $3.47 \pm$ & $3.82 \pm$ & $3.43 \pm$ & $3.81 \pm$ & $3.33 \pm$ & $3.79 \pm$ & $3.72 \pm$ & $3.85 \pm$ & $3.30 \pm$ \\
\hline$\pm \mathrm{SD}$ & 0.03 & 0.11 & 0.05 & 0.07 & 0.79 & 0.70 & 0.35 & 0.05 & 0.06 \\
\hline \multirow[t]{2}{*}{ Friability $(\%) \pm \mathrm{SD}$} & $0.24 \pm$ & $0.38 \pm$ & $0.35 \pm$ & $0.36 \pm$ & $0.36 \pm$ & $0.33 \pm$ & $0.34 \pm$ & $0.37 \pm$ & $0.39 \pm$ \\
\hline & 0.12 & 0.12 & 0.14 & 0.24 & 0.16 & 0.12 & 0.09 & 0.06 & 0.12 \\
\hline Drug Content $(\%)$ & $84.46 \pm$ & $90.24 \pm$ & $88.66 \pm$ & $96.45 \pm$ & $83.16 \pm$ & $98.53 \pm$ & $88.42 \pm$ & $101.80 \pm$ & 93.16 \\
\hline$\pm \mathrm{SD}$ & 0.29 & 0.19 & 0.13 & 0.16 & 0.10 & 0.30 & 0.10 & 0.01 & \pm 0.38 \\
\hline Disintegration Time & $43.66 \pm$ & $29.33 \pm$ & $34.66 \pm$ & $19.00 \pm$ & $39.66 \pm$ & $39.00 \pm$ & $30.33 \pm$ & $13.00 \pm$ & 25.66 \\
\hline$(\mathrm{Sec}) \pm \mathrm{SD}$ & 0.57 & 0.57 & 0.57 & 0.00 & 1.15 & 0.00 & 1.15 & 0.00 & \pm 0.57 \\
\hline Wetting Time & $60.33 \pm$ & $38.33 \pm$ & $44.66 \pm$ & $24.66 \pm$ & $47.33 \pm$ & $27.66 \pm$ & $40.00 \pm$ & $15.33 \pm$ & 36.66 \\
\hline$(\mathrm{Sec}) \pm \mathrm{SD}$ & 1.15 & 0.57 & 1.52 & 1.15 & 0.57 & 1.52 & 1.00 & 0.57 & \pm 0.57 \\
\hline Water Absorption & $61.04 \pm$ & $88.54 \pm$ & $75.56 \pm$ & $115.89 \pm$ & $71.00 \pm$ & & $78.93 \pm$ & $127.11 \pm$ & 97.90 \\
\hline Ratio(R) \pm SD & 0.16 & 0.54 & 0.35 & 0.17 & 0.18 & 0.35 & 0.19 & 0.11 & \pm 0.21 \\
\hline Percentage Drug & 80.94 & $89.92 \pm$ & $84.30 \pm$ & $95.94 \pm$ & $82.84 \pm$ & $93.45 \pm$ & $87.84 \pm$ & $99.67 \pm$ & 91.97 \\
\hline Release $\pm \mathrm{SD}$ & \pm 0.03 & 0.21 & 0.18 & 0.15 & 0.16 & 0.25 & 0.05 & 0.20 & \pm 0.01 \\
\hline
\end{tabular}




\section{Weight variation}

To determine weight variation, twenty tablets were selected randomly from each formulation and were weighed individually using a Shimadzu digital balance (BL-200H).The individual weights were compared with the average weight for obtaining the weight variation.

\section{Hardness}

Hardness was determined by taking six tablets from each formulation, using a Monsanto Hardness Tester.

\section{Friability}

Friability is the measure of tablet strength . The friability of sample of twenty tablets were measured using a Roche friabilator (Veego scientifics, Mumbai). Twenty pre-weighed tablets placed in plastic chamber of friabilator which revolves at a speed of $25 \mathrm{rpm}$ for four minutes (100 revolutions), dropping the tablets to a distance of 6 inches in each revolution. The tablets were then dedusted \& reweighed. Percent friability (\% F) was calculated as follows:

$\%$ Friability $=($ Initial weight - Final weight $/$ Initial weight) x 100 .

\section{Drug content}

There is a great need to monitor the drug content of the tablets so as to predict the potential and efficacy of the particular formulation. The amount of the active content can be determined by taking 10 tablets, they are weighed and powdered. Quantity of powder equivalent to $10 \mathrm{mg}$ of Efavirenz was weighed accurately into a $100 \mathrm{ml}$ volumetric flask and dissolved in methanol and made the final volume with $1 \% \mathrm{w} / \mathrm{v}$ sodium lauryl sulfate (SLS) followed by filtration. The filtrate $(2.5 \mathrm{ml})$ was diluted to $10 \mathrm{ml}$ with $1 \% \mathrm{w} / \mathrm{v}$ SLS \& absorbance was measured at $247.6 \mathrm{~nm}$ (UV-Visible Spectrophotometer, Shimadzu, Japan).

\section{Water absorption ratio}

A piece of tissue paper folded twice was placed in a small petridish containing $6 \mathrm{ml}$ of water. A tablet of known weight was put on the paper $\&$ the time required for complete wetting of tablet was measured. The wetted tablet was then weighed, water absorption ratio $\mathrm{R}$ was determined using the following equation.

$\mathrm{R}=[(\mathrm{Wa}-\mathrm{Wb}) / \mathrm{Wb}] \times 100$
Where $\mathrm{W}_{\mathrm{b}}$ is weight of tablet before water absorption \& $\mathrm{W}_{\mathrm{a}}$ is weight of tablet after water absorption.

In-vitro dissolution studies:

The dissolution rate of Efavirenz from the tablets was studied in $0.1 \mathrm{~N} \mathrm{HCl}$ using USP XXIII dissolution test apparatus employing paddle stirrer (type-II). In this one tablet containing $200 \mathrm{mg}$ of Efavirenz, a speed of $50 \mathrm{rpm}$ \& a temperature $37^{\circ} \pm 0.5^{\circ} \mathrm{C}$ was employed. A $10 \mathrm{ml}$ of aliquot of dissolution medium was withdrawn at different time intervals $(0,5,10,15,20 \& 30 \mathrm{mins})$ and replaced with the equal volume of fresh medium. The samples were filtered \& analyzed for Efavirenz content by measuring the absorbance at $246.5 \mathrm{~nm}$.Drug concentration was calculated from the standard calibration curve. The release studies were performed in triplicate.

\section{Stability studies}

The purpose of stability testing is to provide evidence on how the quality of a drug substance or drug product varies with time under the influence of a variety of environmental factors such as temperature, humidity and light, enabling recommended storage conditions, re-test periods and shelf-lives. Generally, the observation of the rate at which the product degrades under normal room temperature requires a long time. To avoid this undesirable delay, the principles of accelerated stability studies are adopted.

In order to determine the change in hardness, disintegration time, drug content \& \% drug release on storage, stability study of optimized formulation F8 were carried out at $40^{\circ} \mathrm{C}$ in a humidity chamber having $75 \% \mathrm{RH}$ (Table IV). Samples were withdrawn at regular intervals during the study of 90 days. The optimized formulation F8 was evaluated for hardness, disintegration time, drug content and percentage drug release.

\section{Results and discussion}

Several technologies are available to manufacture orally disintegrating tablets. The most common preparation methods are molding, lyophilization or freeze drying, direct compression, spray drying and sublimation. In the present investigation ODTs of Efavirenz were prepared by direct compression method. Formulation optimization was done by using a $2^{3}$ full factorial design employing crospovidone, croscarmellose sodium and sodium starch glycolate as superdisintegrants along with directly compressible mannitol, which was used to enhance the mouth feel. A total of eight formulations and one extra design check point 
Table IV. Stability study results for odt's under accelerated condition.

\begin{tabular}{|c|c|c|c|c|}
\hline Parameter & Initial & $1^{\text {st }}$ month & $2^{\text {nd }}$ month & $3^{\text {rd }}$ month \\
\hline $\begin{array}{l}\text { Hardnęs } \\
\left(\mathrm{kg} / \mathrm{cm}^{2}\right) \pm \mathrm{SD}\end{array}$ & $3.85 \pm 0.050$ & $3.65 \pm 0.078$ & $3.51 \pm 0.050$ & $3.39 \pm 0.350$ \\
\hline $\begin{array}{l}\text { Disintegration } \\
\text { Time }(\mathrm{Sec}) \pm \mathrm{SD}\end{array}$ & $13.00 \pm 0.000$ & $13.66 \pm 0.577$ & $16.33 \pm .0 .577$ & $19.33 \pm 0.577$ \\
\hline $\begin{array}{l}\text { Drug Content } \\
(\%) \pm \mathrm{SD}\end{array}$ & $101.80 \pm 0.010$ & $100.71 \pm 0.097$ & $100.57 \pm 0.120$ & $100.33 \pm 0.125$ \\
\hline $\begin{array}{l}\text { Percentage Drug } \\
\text { Release }(\%) \pm \mathrm{SD}\end{array}$ & $99.67 \pm 0.020$ & $99.64 \pm 0.002$ & $99.47 \pm 0.007$ & $98.24 \pm 0.170$ \\
\hline
\end{tabular}

formulation (F9 to check validity of the developed polynomial equation) were designed.

Powder blends were evaluated for the flow parameters such as angle of repose, loose bulk density, tapped bulk density, Carr's index and Hausner's ratio. As the material was free flowing, angle of repose values were found to be $<30^{\circ}$, Carr's index $<15$ and Hausner's ratio $<1.25$.

The tablets were evaluated for thickness, diameter, weight variation, hardness, friability, drug content, wetting time, water absorption ratio, disintegration time and in vitro dissolution studies.

Tablets obtained were of uniform weight with acceptable variation as per IP specification $( \pm 5 \%)$.

Drug content was found to be in the range 83 to $102 \%$, which is within acceptable limits. Hardness of the tablets was fond to be 3.0 to $4.0 \mathrm{~kg} / \mathrm{cm}^{2}$. Friability below $1 \%$ was an indication of good mechanical resistance of the tablets. Formulation F8 was found to be promising and displayed a disintegration time of $13 \mathrm{sec}$ which facilitates faster disintegration in the mouth.
Based on the results of all 9 formulations, optimization of the ODT formulation has been done using a $2^{3}$ full factorial design (F1 to F8). Design expert 8.0.7.1 trail version software was used to develop a polynomial equation for the dependent variables wetting time, disintegration time and percentage drug release at $30 \mathrm{~min}$. Formulation F8 containing 5\% w/w $\mathrm{CP}, 5 \% \mathrm{w} / \mathrm{w} \mathrm{CCS}$ and $8 \% \mathrm{w} / \mathrm{w} \mathrm{SSG}$ was found to be promising with an wetting time of $15 \mathrm{sec}$, disintegration time $13 \mathrm{sec}$ and percentage drug release at $30 \mathrm{~min}$ of $99.67 \%$ against extra design check point formulation.

In vitro dissolution parameters, including dissolution efficiency of the promising formulation F8 \& extra design check point formulation F9 are shown in Table V and the dissolution profile depicted in figure 4, this data reveals that over all the formulation F8 has shown nearly faster drug release when compared to extra design check point.

DSC analysis indicated that the drug is compatible with superdisintegrates. The short term stability studies of the above formulation indicated that there are no significant changes in hardness, disintegration time, drug content and in vitro dissolution studies at the end of the three month period.

Table V. Evaluation of extra design check point formulation F9 and optimized formulation F8

\begin{tabular}{lccc}
\hline Response parameter & Formulation code & Predicted value & Experimental value \\
\hline Wetting Time(sec) & F9 & 37.22 & $36.66 \pm 0.577$ \\
$(\mathrm{~kg} / \mathrm{cm} 2) \pm \mathrm{SD}$ & F8 & 37.28 & $15.53 \pm 0.577$ \\
& & & \\
Disintegration & F9 & 30.48 & $25.66 \pm 0.577$ \\
time(sec) & F8 & 29.66 & $13.00 \pm 0.00$ \\
Percentage drug & F9 & 89.61 & $91.57 \pm 0.011$ \\
release at 30 min & F8 & 90.30 & $99.67 \pm 0.02$ \\
\hline
\end{tabular}




\section{Factorial design}

Polynomial equation for $2^{3}$ full factorial design with three independent variable, that is amount of crospovidone (X1), croscarmellose sodium (X2) and sodium starch glycolate (X3), a statistical model incorporating interactive \& polynomial terms was used to evaluate the responses.

$\mathrm{Y}=\mathrm{B} 0+\mathrm{B} 1 \mathrm{X} 1+\mathrm{B} 2 \mathrm{X} 2+\mathrm{B} 3 \mathrm{X} 3+\ldots+\mathrm{B} 12 \mathrm{X} 1 \mathrm{X} 2+\mathrm{B} 13 \mathrm{X} 1 \mathrm{X} 3+\mathrm{B} 2$ $3 \mathrm{X} 2 \mathrm{X} 3+\ldots+\mathrm{B} 123 \mathrm{X} 1 \mathrm{X} 2 \mathrm{X} 3$

B1 is estimated coefficient for the factor X1 While B2 \& B3 for the factors $\mathrm{X} 2$ and $\mathrm{X} 3$ respectively. The main effects (X1,
X2 \& X3) represent the average result of changing one factor at a time from its low to high value. The interaction terms show how the response changes when three factors are simultaneously changed.

The non-significant response coefficients were deleted and the following significant polynomial response equation(s) for wetting time, disintegration time and percentage drug release at 30 minutes were generated.

The negative sign for coefficient of X1, X2 and X3 indicates that as the concentration of disintegrant increase, disintegration time, wetting time decreases and percentage drug release at $30 \mathrm{~min}$ increases. The data clearly indicates

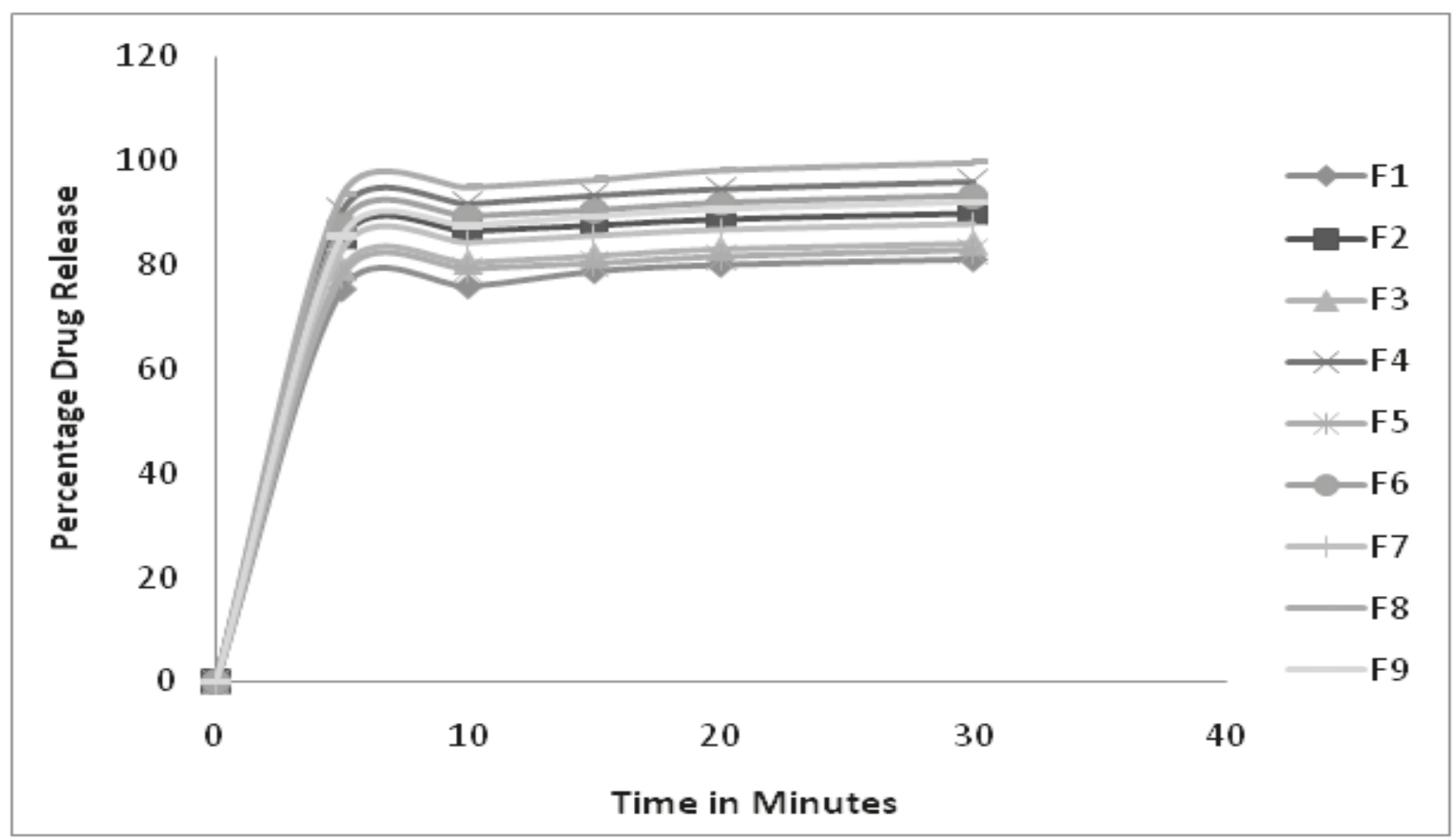

Fig. 1. Comparative percentage drug release profile of all formulations
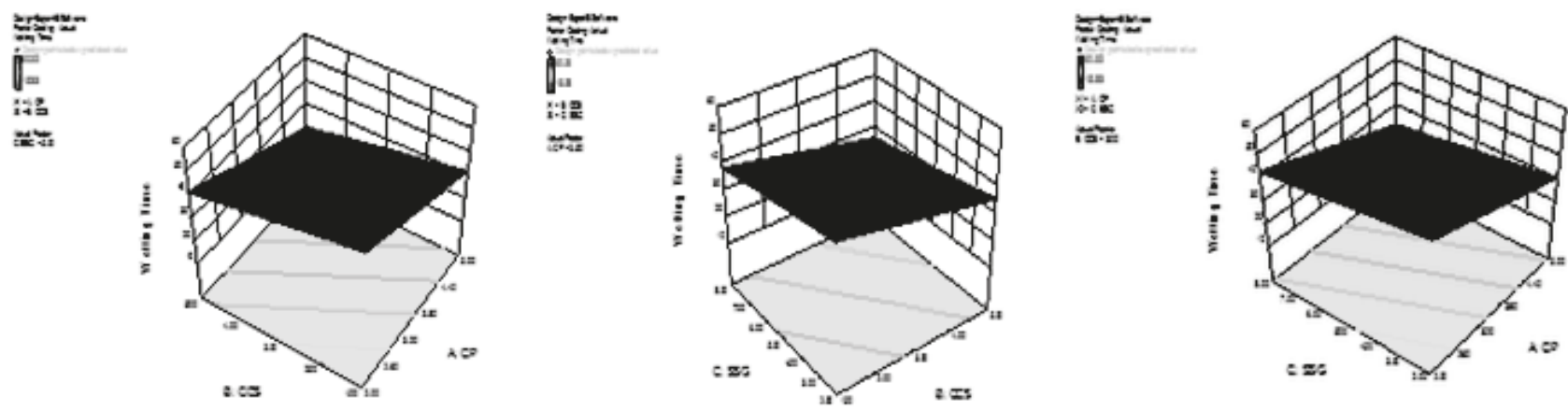

Fig. 2. Response surface plots showing influence of independent variables on response parameter of orodissolving formulations -wetting time 

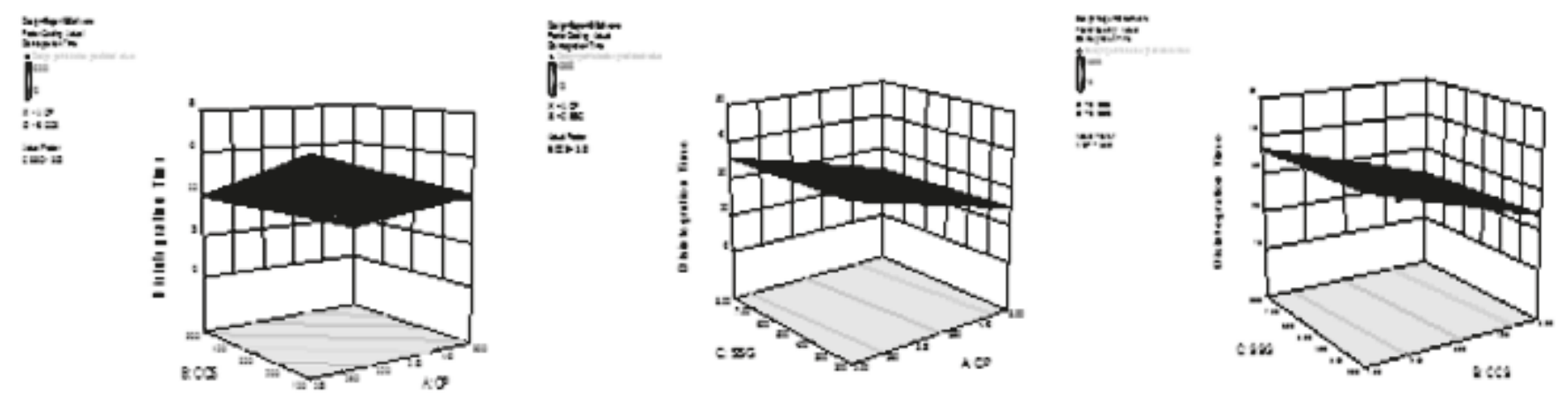

Fig. 3. Response surface plots showing influence of independent variables on response parameter of orodissoloving formulations- disintegration time.
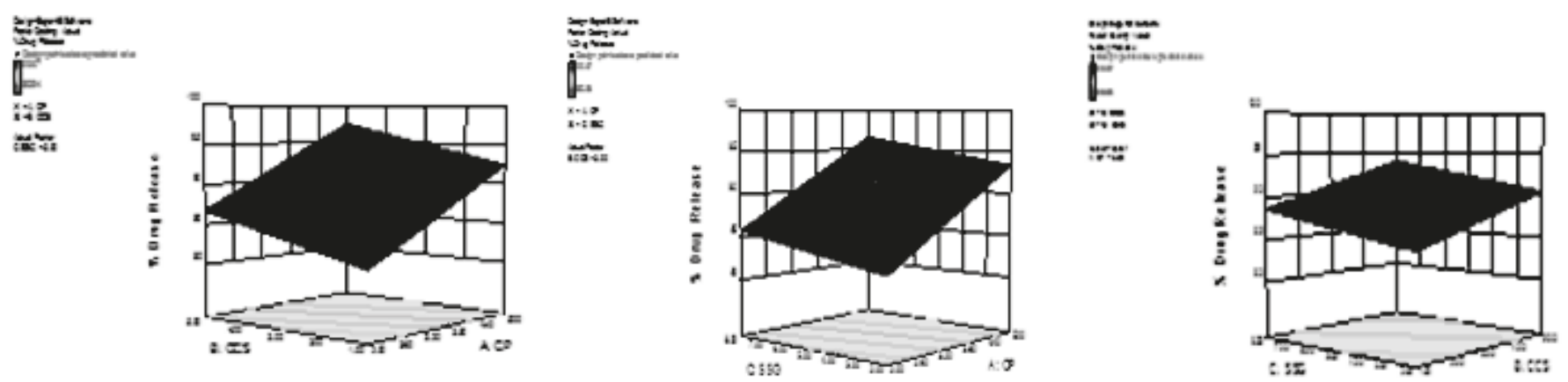

Fig. 4. Response surface plots showing influence of independent variables on response parameter of orodissolving formulations-percentage drug release at 30 minutes.

that wetting time, disintegration time and percentage drug release values are strongly dependent on the selected variables. Validity of the above equation was verified by designing extra design check point formulation (F9) and determining the wetting time, disintegration time and percentage drug release at $30 \mathrm{~min}$. The wetting time, disintegration time and percentage drug release at $30 \mathrm{~min}$ values predicted from this formulation are $37.22 \mathrm{sec}, 30.48 \mathrm{sec}$ and $89.61 \%$ were observed from experimental values $36.66 \mathrm{sec}, 25.66 \mathrm{sec}$ and $97.57 \%$ respectively. The closeness of the predicted \& experimental values for F9 in the method drug release at $30 \mathrm{~min}$. Response surface plots showing influence of independent variables on response parameter of Orodissolving formulations are shown in Fig. 2, 3 and 4.

It is thus concluded that, by adopting a systemic formulation approach, an optimum point can be reached in the shortest time with minimum efforts. Direct compression technique would be an affective approach compared with the use of more expensive adjuvant in the formulation of ODT with improved drug dissolution, patient compliance, convenience and acceptability.

Wetting Time $=37.22-10.79 \mathrm{X}_{1}+\left(-6.13 \times\left[\mathrm{X}_{2}\right]\right)-\left[4.71 \times\left(\mathrm{X}_{3}\right)\right]+\left[0.187 \times\left(\mathrm{X}_{1} \mathrm{X}_{2} \mathrm{X}_{3}\right)\right] \ldots \ldots \ldots \ldots . . \mathrm{eq} 1$

Disintegration Time $=30.48-6.00 \mathrm{X}_{1}+\left[-6.83 \times\left(\mathrm{X}_{2}\right)\right]+\left[-0.58 \times\left(\mathrm{X}_{3}\right)\right]+\left[-1.92 \times\left(\mathrm{X}_{1} \mathrm{X}_{2} \mathrm{X}_{3}\right)\right] \ldots \ldots . . . . \mathrm{eq} 2$

Percentage drug release at $30 \mathrm{~min}=89.61+5.38 \mathrm{X} 1+[2.58 \times(\mathrm{X} 2)]+[1.59 \times(\mathrm{x} 3)]+\left[-0.18 \times\left(\mathrm{X}_{1} \mathrm{X}_{2} \mathrm{X}_{3}\right)\right] \ldots . . \mathrm{eq} 3$

indicates validity of observed equation for the dependent variables. The computer generated response surface for the dependent variable were shown in the figure. The results of a $2^{3}$ full factorial design reveal that amount of crospovidone (X1), amount of croscarmellose sodium (X2) and sodium starch glycolate (X3), significantly affect the dependent variables wetting time, disintegration time and percentage

\section{References}

Aulton M E. Pharmaceutics: The design and manufacture of medicines, ${ }^{3 \mathrm{r}}$ dedition, Churchill Livingstone, New York, 2007, 168-179, 353-356. 
Ansel S C, Allen L V and Popovich N G. Pharmaceutical dosage form and drug delivery systems, $8^{\text {th }}$ edition, Lippincott Williams \& Wilkins, New York, 2009, 234-238.

Gilbert S, Banker C and Rhodes T. Modern Pharmaceutics, $4^{\text {th }}$ edition, Marcel Dekker Inc, New York, 2005, 121, 287-324.

Kawtikwar P S, ZadeP S and Sakarkar D M. Formulation, Evaluation and Optimization of Fast dissolving tablet containing Tizanidine Hydrochloride, International Journal of PharmTech Research, 2009, 1(1), 34-42.

Lachman L, Lieberman A, Herbert K and Joseph L. The Theory and Practice of Industrial Pharmacy, $3^{\text {rd }}$ edition, Varghese Publishing House, Mumbai, 1987, 299-302.

Manavalan R and Ramaswamy S. Physical Pharmaceutics, $2^{\text {nd }}$ edition, vignesh publisher, Chennai, 2001, 288-299.

Szakonyia G and Zelkob R. Prediction of Oral Disintegration Time of Fast Disintegrating Tablets Using Texture Analyzer and Computational Optimization, International Journal of Pharmaceutics, 2013, 346-353.
Venkateswara Reddy and Ramana Murthy. Enhancement of Dissolution Rate of Efavirenz by Solid Dispersion Technique, International Journal of Pharmacy and Biological Sciences, 2012, 185-190.

Vineet Bhardwaj, Mayank Bansal and P K Sharma. Formulation and Evaluation of Fast Dissolving Tablets of Amlodipine Besylate Using Different Super Disintegrants and Camphor as Sublimating agent Agents, American-Eurasian Journal of Scientific Research, 2010, 264-269.

Zade P S, P S Kawtikwar and D M Sakarkar. Formulation, Evaluation and Optimization of Fast Dissolving Tablet Containing Tizanidine Hydrochloride, International Journal of PharmTech Research, 2009, 34-4

Received: 13 October 2013; Revised: 07 April 2014; Accepted: 03 June 2014. 